\title{
Making Interpretivism Visible: Reflections after a Decade of the Methods Café
}

Kevin Funk, University of the District of Columbia

ABSTRACT More than a decade after the observation that an "interpretive turn" was percolating through political science, there are clear indications of growth in the perceived legitimacy of interpretive scholarship. Both accompanying and contributing to interpretivism's ascent has been the regular staging of Methods Cafés at various conferences in and beyond the discipline. First held at the 2005 meeting of the Western Political Science Association, the Methods Café subsequently landed at the 2006 conference of the American Political Science Association. The Methods Café has become an institutionalized feature of these and other conferences. This reflection looks at the past, present, and future of these events, as well as the key role they have played in making interpretivism visible in the discipline. In particular, I highlight their function as non-hierarchical intellectual spaces that promote teaching, learning, and interpretivist community building. Further, I offer friendly but not uncritical commentary on the successes and limitations of the Methods Café.

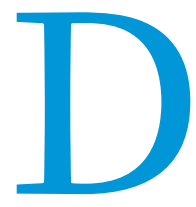

uring the decade following the observation that an "interpretive turn" was percolating through political science, research in-and about-this previously marginal (and marginalized) intellectual tradition has gained significant recognition (Yanow and Schwartz-Shea 2006).

Understood not only as a broad label for a diverse set of methodological approaches but also as encompassing a series of epistemological and ontological claims, interpretivism is premised on the notion-as Clifford Geertz put it, channeling Max Weber-"that man is an animal suspended in webs of significance he himself has spun." This implies pursuing "not an experimental science in search of law but an interpretive one in search of meaning" (quoted in Yanow 2014, 6).

Accordingly, interpretivism's main focus is on "the centrality of meaning in human life" and the myriad ways in which actors construct their life-worlds (Yanow and Schwartz-Shea 2014, xiv). Unlike positivism, it does not privilege parsimony and generalizability over context and nuance. This makes interpretivist approaches highly appropriate for pursuing certain lines of inquiry, especially those related to meaning-making practices.

Clear indications of growth in the perceived legitimacy of interpretivist scholarship include the 2008 founding of the Interpretive Methodologies and Methods Conference Group through the American Political Science Association (APSA);

Kevin Funk is assistant professor of political science at the University of the District of Columbia. He can be reached at kevin.funk@gmail.com. the establishment of the Routledge Series on Interpretive Methods; and the increasing citation counts of interpretivist works (Lynch 1999; Oren 2003; Pachirat 2011; Schaffer 1998). Likewise, interpretivist research is increasingly published by the discipline's most esteemed presses and journals (Majic 2017; Smith 2019).

Both accompanying and contributing to interpretivism's ascent is the regular staging of Methods Cafés at conferences both in and beyond political science. First held at the 2005 meeting of the Western Political Science Association (WPSA), the interpretivismfocused Methods Café was brought by its creators-Dvora Yanow (Wageningen University) and Peregrine Schwartz-Shea (University of Utah)-to the 2006 APSA Annual Conference. Notably, this occurred long before "cafés" were introduced at APSA.

These Methods Cafés have become annual events at both conferences. Furthermore, in the case of APSA, they have enjoyed the support of the qualitative and multimethod research section as well as official APSA sponsorship-that is, participation does not count against conference presentation limits and the Café has a guaranteed spot on the program. Breaking with the traditional hierarchies of conference panels, the Cafés seek to function as informal spaces in which attendees circulate freely among thematically organized tables staffed with conversation leaders.

Inspired by the original events, diverse iterations of Methods Café-style gatherings-with varying levels of interpretivist content-have since been held at conferences of the International Studies Association (ISA), International Political Science Association, and Law and Society Association, among others. 
Shortly after the inauguration of the WPSA and APSA Methods Cafés, the events' co-organizers and intellectual authors, Yanow and Schwartz-Shea, published a brief commentary piece in PS: Political Science \& Politics (2007) that provided a genealogy of these then-fledgling events. Slightly more than a decade later, the Methods Cafés have become an institutionalized feature of these and other conferences. My similarly brief reflection analyzes the past, present, and future of the Methods Cafés, as well as their role in making interpretivism visible in political science (and beyond). to incorporate new participants and ensure that the program is diverse vis-à-vis race, gender, and intellectual interests.

Of the more than 50 table topics that have been featured at APSA Methods Cafés, the following have been offered at least six times: archival research, discourse analysis, feminist methods, field research, intersectionality, interviewing, postcolonial analysis, and teaching qualitative-interpretive methods. Other topics, including sexualities, and interpretive methods in political theory, have been offered only once. This is not due to a lack of importance but rather factors such as attendance figures and

\section{Inspired by the original events, diverse iterations of Methods Café-style gatherings-with varying levels of interpretivist content-have since been held at conferences of the International Studies Association (ISA), International Political Science Association, and Law and Society Association, among others.}

These reflections are based on interviews with past and present organizers, analysis of how the Methods Cafés evolved, and my experience at the annual APSA events: first, in 2015 and 2016 as a graduate student and "guest" and, subsequently, in 2017 as a junior faculty member and participant observer circulating, listening, engaging in dialogues, and taking notes. My aims were to immerse myself for the purposes of this article and to learn more about interpretivism due to my own intellectual interests relating to class consciousness, global imaginaries, and socio-spatial analysis.

Based on these experiences, I highlight the Methods Cafés' role as non-hierarchical intellectual spaces that promote teaching, learning, and interpretivist community building. To conclude, I offer friendly but not uncritical commentary on their successes and limitations.

\section{THE METHODS CAFÉ AS PRAXIS}

Several features of the Methods Café are worth highlighting. Most importantly, it functions as a "café" by providing a space for informal conversation. ${ }^{1}$ A "host" oversees the event and introduces newcomers to its format. Carefully chosen "specialists" sit at thematically labeled tables, waiting for "visitors" with whom to engage. The visitors are free-and encouraged-to circulate as they please, thereby creating an environment akin to "several roundtables...happening at the same time in the same space" with interpretivism serving as the unifying thread (Yanow and Schwartz-Shea 2007, 383-85). As the handout for the 2017 APSA event noted, "As a café visitor, you may arrive at any point, visit any table you like, and stay as long as you like."

From the beginning, the idea has been to represent the diversity of political science subfields as well as interpretivism itself. Many topics have been featured at nearly every Café whereas others have come and gone. This variation is a result of the interests of volunteer specialists, postevent feedback gathered independently by organizers, and a determination of which themes are of greater interest to attendees (based on the number of those who "vote with their feet" and choose to sit at a particular table). Reminiscent of snowball sampling, organizers draw from past participants and their acquaintances in making the schedule, prioritizing those who are pedagogically inclined. They also strive occasional difficulties in scheduling specialists. Of course, these topics may reappear in the future. Similarly, of the more than 6o scholars who have served as specialists, some participate every year whereas others have done so only once.

This variability, flexibility, and-indeed-experimentation comprise the hallmark of the Methods Café and are among its most exciting features. As Schwartz-Shea remarked during our 2017 interview, part of their ambition was to include "methods that seemed innovative/potentially useful in political science but that didn't seem to be on most scholars' radars."

The Methods Cafés also erode traditional academic hierarchies by bringing together everyone from graduate students to distinguished professors in a relaxed environment that facilitates genuine conversation. In this space, as Yanow and Schwartz-Shea (2007, 383) observed, "[w]e are all discussants!" Furthermore, as noted on the promotional "What Is the Methods Café?" handout, specialists come prepared to address all manner of questions, ranging from what a particular method "is" and how to advise students who are pursuing interpretivist research to how to conduct data analysis. Although information is not collected on attendees' positions and ranks, my observations indicate that the Cafés have been successful in attracting diverse audiences.

\section{GOALS, VISION, TRAJECTORIES}

Undoubtedly, the initial APSA Methods Cafés were modest in size. The first featured seven specialists, each representing a distinct topic; the second increased to 12 specialists who encompassed 10 thematic areas. In contrast, recent years reveal consistent lineups of 20 to 25 specialists and 12 to 15 topics, with nearly 100 visitors. Thus, they have grown considerably in terms of both thematic coverage and participation.

For example, the 2017 APSA Methods Café-co-organized, for the first time, by Samantha Majic (CUNY-John Jay College) and Timothy Pachirat (University of Massachusetts Amherst) ${ }^{2}$ featured 24 specialists representing 16 different subjects (including, for the first time, tables for research funding and publishing).

These two new tables were repeated at the 2018 APSA Methods Café, with the former featuring representatives from the Social Science Research Council and National Science Foundation and the latter featuring the editor-in-chief of a university press, the editor 
and associate editor of Perspectives on Politics, and an associate editor of American Political Science Review. Similarly-since 2017 and 2018, respectively-the event has benefited from the sponsorship of Routledge and Cambridge University Press. Such interpretivist inroads within the political science mainstream would have been unthinkable only a few years ago.

The approach to recruiting would-be attendees, from the beginning, has been ecumenical. Tellingly, the publicity flyer for the 2017 Methods Café-which is similar to those produced before and since-began as follows:

Curious how to incorporate ethnography into your next project or what a feminist approach to your research question might look like? Ever wondered what critical race studies or postcolonial studies might add to your work? Interested in meeting with journal editors to learn how to best present your research for publication?

As implied, the aim is not to "convert" skeptical participants to interpretivism. Rather, it is to highlight how often-overlooked approaches can shed additional light on topics of perennial interest as well as introduce new perspectives, methods, and ways of knowing. This is part of what makes the Cafés necessary: conferences for the foreseeable future; the model is also spreading, both conference-wise and topically.

Perhaps the best measure of success, however, is the extent to which the Methods Cafés have contributed to the normalization and growth of interpretivism within political science. That is, how helpful have the Cafés been in creating intellectual and methodological "space" within a discipline whose mainstream has long been dominated by positivist work (King, Keohane, and Verba 1994; Van Evera 1997)? Are political scientists increasingly willing to not only conduct interpretivist-inspired research but also to use the "I-word" to describe it?

In this sense, the goal of the Methods Cafés can be seen as effecting change within the discipline: not, of course, to establish a new orthodoxy but rather to create a more pluralistic environment in which non-positivist approaches, methods, ontologies, and epistemologies are visible, valued, and treated as co-equals. Or, in tandem, to facilitate cross-pollination between interpretivist and positivist scholars to promote the exploration of "mixed" approaches (Barkin and Sjoberg 2017).

Fundamental to achieving this parity is increasing the self-confidence of those who may feel the need to retreat from the "interpretivist" label due to fear-real or imagined-that openly adopting it will hinder their ability to publish, navigate the job

\section{This is part of what makes the Cafés necessary: approaches such as "political ethnography" and "critical/cultural media analysis" may be of potential interest to all political scientists but, without advocacy on their behalf, their most likely fate is continued marginalization.}

approaches such as "political ethnography" and "critical/cultural media analysis" may be of potential interest to all political scientists but, without advocacy on their behalf, their most likely fate is continued marginalization.

Naturally, the longevity of the Methods Cafés, along with attendance figures and the range of topics offered, are signs of "success." Another sign is the fact that both specialists and visitors consistently rank the Cafés highly on postevent feedback forms, with many remarking that it is their favorite conference event. Some have noted that participating is their primary reason for attending these conferences.

Representative of this positive assessment are comments provided on the evaluation form by a first-time specialist, who noted: "I appreciated and enjoyed the 'fellow-feeling' in the room....It felt like we learned a lot from each other from those conversations, which was very satisfying." Another wrote in a postevent email to the hosts: "I can't tell you how much the café meant to me. The time flew by and I left that room feeling as though I was reentering the familiar APSA-with its unique mixture of substance, posturing, and pain-from another world where it was all about generosity and the work."

Further signs of vitality include the fact that the Methods Cafés have not only survived but also thrived during the previously mentioned transition to new leadership, as well as the spread of the café model to other institutional spaces and thematic areas (e.g., ISA's regular staging of the Critical Security Studies Methods Café beginning in 2013 and a Mentoring Café for scholars from the Global South). In other words, not only does it appear that Methods Cafés will be a recurring feature of APSA and WPSA market, obtain grants, and so on. In this regard, it is fitting to note that earlier Methods Cafés featured a break in the middle for participants to make announcements related to publications and job searches. However, this feature has been discontinued in recent years because participants had too much to share in the allotted time-another sign of interpretivism's dynamism.

Thus, true to the intent of the originators, the Methods Cafés function as a community-building exercise-a purpose implied by the "café" label-that seeks to empower everyone from graduate students to established scholars to feel comfortable to pursue their intellectual interests without the constraints of the "positivist straitjacket" (Oren 2009). Again, this effort does not necessarily imply eschewing positivism and certainly does not seek to replace it. Rather, in the interest of true pluralism, the goal is to open up intellectual space for alternative ways of thinking and knowing.

The Methods Cafés also aim to cultivate among participants the ability to explain, justify, and defend their work to noninterpretivist audiences and to enunciate a broad and "positive (in the celebratory sense) delineation of interpretive techniques and their philosophical grounding" that moves beyond defensiveness and a sense of inferiority vis-à-vis the positivist mainstream (Yanow and Schwartz-Shea 2014, xiv; emphasis added). Hence, participants attend the Cafés both to educate themselves and to learn how to educate others.

Notably, the previously mentioned flyer refers to the Cafés "friendly vibe," which is meant to facilitate "small group discussions, networking, and mentoring support." It continues: "We extend an invitation in particular to doctoral students looking 
for assistance with any aspect of a research project, as well as to faculty with questions about researching and/or teaching these subjects." As Yanow and Schwartz-Shea observed during an interview that I conducted with them along the sidelines of the 2017 APSA conference, these events often serve as a "supportive space" for those whose home departments and institutions may not include other interpretivist scholars or be sufficiently friendly to non-positivist research more generally. vis-à-vis non-"mainstream" theoretical traditions (Sclofsky and Funk 2018). Yet, this exchange nevertheless highlights the ways in which the Methods Cafés seek to create intellectual space within political science for non-positivist ways of thinking. In turn, based on the previously mentioned trends-including increasing use of the "I-word" and the Methods Cafés' own consolidation, institutionalization, and proliferation-there certainly appears to be "progress" in this regard.

\section{The Methods Cafés also aim to cultivate among participants the ability to explain, justify, and defend their work to non-interpretivist audiences and to enunciate a broad and "positive (in the celebratory sense) delineation of interpretive techniques and their philosophical grounding" that moves beyond defensiveness and a sense of inferiority vis-à-vis the positivist mainstream (Yanow and Schwartz-Shea 2014, xiv; emphasis added).}

In this vein, I am reminded of an interaction I witnessed at the teaching methods table during the 2017 APSA Methods Café. The specialist, Ido Oren (University of Florida), fielded a series of questions from an anxious interlocutor who perceived that her colleagues were hostile to less "scientific" scholarship. Oren's response was twofold. First, he empathized with her situation and expressed displeasure with how the language of "science" and "scientific neutrality" often is deployed as a gate-keeping device within political science to police the boundaries between "legitimate" (positivist) and "illegitimate" (non-positivist) ways of knowing. This, he noted, can naturally lead interpretivist scholars to discard the language of "science" entirely.

Yet, the second part of his response pushed in the opposite direction by posing the following question: If indeed "man is an animal suspended in webs of significance he himself has spun," then why is it less "scientific" to study the human condition through interpretive approaches that are more sensitive than their positivist counterparts to how people actually think and act?

That is, why should a (positivist) study based on standardized surveys that do not take into account context, culture, and the "social construction of reality" (Berger and Luckmann 1967) automatically be considered more "scientific" than an interpretive project that does? The same goes for research in the former tradition that neglects to interrogate what key terms-such as "democracy" (Schaffer 1998) and "globalization" (Funk 2015)-actually mean to individuals situated in particular environments. Positivist studies that assume stable definitions across axes of difference in fact may overlook how survey responses can reflect distinct cultural logics and normative assumptions. This is evident, for example, vis-à-vis Schaffer's (1998) exploration of how meanings of "democracy" in Senegal often deviate from conventional political science understandings of the term. In turn, if the Geertzian ontology of the human experience suggested by interpretivists is sound, then why not claim an equal right to the mantle of (social) science-at least, of course, vis-à-vis research projects relating to culture, identity, and meaning making?

Nothing about the material conditions in the questioner's home institution will have changed due to this conversation. Furthermore, of course the discipline has yet to achieve methodological pluralism, and various pernicious forms of intellectual gatekeeping remain. A similar marginalization also occurs

\section{DIFFICULTIES, CHALLENGES, LIMITATIONS-AND FUTURE PATHWAYS}

It also is necessary to acknowledge the difficulties that confront the Methods Cafés, which implicate both larger structural issues that characterize the discipline as a whole and idiosyncratic factors that appear difficult to account for let alone control.

- Despite the intent of the organizers to create a free-flowing environment in which attendees feel comfortable moving among tables at their leisure, many stay seated at the same place during the entire event. This, as Majic commented to me, is the organizers' "main challenge." In other words, there is no problem with initiating conversations but, perhaps, with ending them. Organizers speculate that part of this reluctance relates to not wanting to appear "rude" in the eyes of specialists. To put attendees more at ease, hosts have become especially forthright in issuing mid-event announcements about the social acceptability of mobility within the café environment and also reminding specialists to encourage visitors to circulate.

- Mirroring broader disciplinary trends-and despite the organizers' efforts-it has proven difficult to make the Cafés sufficiently diverse in terms of the demographic composition of specialists and the political science subfields. In the latter regard, Yanow and Schwartz-Shea pointed during our interview to a "hole" regarding American politics, where positivism is more deeply entrenched.

- Similarly, certain topics have failed to gain traction at APSA and/or WPSA conferences. For example, feminist methods have taken root at the WPSA Methods Café but, for reasons unknown, sexuality, disability studies, and postcolonialism have not. Public policy has not proven to be a popular topic at either event, even though there is a successful annual conference dedicated to interpretive policy analysis in Europe. In some cases, these dynamics may be attributed simply to randomness, which organizers seek to address through continued thematic experimentation. However, in other cases, they reflect broader structural problems-such as, in the case of postcolonialism, the frequent marginalization of Global South voices-that require focused attention. 
- As noted vis-à-vis the aforementioned conversation at the teaching methods table, Café interactions occur within a broader context that may not be entirely friendly to interpretivism. Thus, specialists must balance their advocacy with the recognition that visitors must navigate dissertation committees, departments, institutions, professional associations, funding agencies, and job markets that likely will include individuals who are unfamiliar with interpretivism and who may be less than supportive of interpretive research-or even dismissive of or hostile toward it. For example, what can be said to graduate students whose intellectual interests are pushing them in an interpretivist direction, but whose advisers are pressuring them to conduct positivist research? Of course, this is not an easy needle for specialists to thread. Furthermore, these are particularly salient issues for those who are more professionally "vulnerable": graduate students and early-career scholars (Yanow and Schwartz-Shea 2007, 385).

Yet, despite these difficulties, challenges, and limitations, we also can point to successes, including the Methods Cafés' very survival within an often-skeptical discipline and their role in making interpretivism more visible. The fact that the "I-word" is an increasingly acknowledged-if not always welcome-part of the political science repertoire speaks volumes about the Methods Cafés' role, which Yanow and Schwartz-Shea referred to during our interview as a "non-formal educational venture" that has "put other ways of thinking on the discipline's map."

According to current organizers, future Methods Cafés will continue to experiment thematically while also seeking to address the obstacles that have prevented interpretivism from further expanding its reach. Thus, just as the Methods Cafés have been instrumental in putting topics on conference programsand the disciplinary map-that were previously absent, we can expect further boundary pushing to continue. Future Cafés also will continue advancing the larger projects of raising disciplinary consciousness concerning interpretivism and diversifying and making more pluralistic the political science landscape.

Recently, a debate has emerged concerning the Data Access and Research Transparency (DA-RT) initiative. Proponents claim that this will enhance the credibility of political science research by formalizing data-sharing practices among adhering journals based on the principle of "openness" (Elman and Kapiszewski 2014). Opponents such as Jeffrey Isaac (2015, 276-77), then-editor of Perspectives on Politics and a past Methods Café participant, in turn have suggested that this project is based on "recent efforts to promote a rather narrow conception of political science" that is more concerned with positivist views of "methodological rigor" than fostering a discipline characterized by "intellectual vitality and...the willingness to take intellectual risks in the name of being interesting."

DA-RT's would-be growth appears destined to generate further arguments concerning a complicated set of practical, ethical, and methodological issues. In this context, the Methods Cafés promise to provide a critical forum in which scholars can gather to sharpen their positions, formulate responses, and coordinate efforts to ensure that any such initiatives consider the unique qualities of research conducted in the interpretivist tradition.

\section{NOTES}

1. The name "Methods Café" was suggested by Cecelia Lynch (University of California, Irvine) and is credited by Yanow and Schwartz-Shea with helping to enable the event's success.

2. The current co-organizers of the WPSA Methods Café are Julie Novkov (University at Albany, SUNY) and Brent Steele (University of Utah).

\section{REFERENCES}

Barkin, J. Samuel, and Laura Sjoberg (eds.). 2017. Interpretive Quantification: Methodological Explorations for Critical and Constructivist IR. Ann Arbor: University of Michigan Press.

Berger, Peter L., and Thomas Luckmann. 1967. The Social Construction of Reality: A Treatise in the Sociology of Knowledge. New York: Anchor.

Elman, Colin, and Diana Kapiszewski. 2014. "Data Access and Research Transparency in the Qualitative Tradition." PS: Political Science \& Politics 47 (1): 43-47. Available at https://doi.org/10.1017/S1049096513001777.

Funk, Kevin. 2015. "The Global South Is Dead, Long Live the Global South! The Intersectionality of Social and Geographic Hierarchies in Global Capitalism." New Political Science 37 (4): 582-603. Available at https://doi.org/10.108o/o73931 48.2015.1089031.

Isaac, Jeffrey C. 2015. "For a More Public Political Science." Perspectives on Politics 13 (2): 269-83. Available at https://doi.org/10.1017/S1537592715000031.

King, Gary, Robert Keohane, and Sidney Verba. 1994. Designing Social Inquiry: Scientific Inference in Qualitative Research. Princeton, NJ: Princeton University Press.

Lynch, Cecelia. 1999. Beyond Appeasement: Interpreting Interwar Peace Movements in World Politics. Ithaca, NY: Cornell University Press.

Majic, Samantha. 2017. "Participating, Observing, Publishing: Lessons from the Field." PS: Political Science \& Politics 50 (1): 103-8. Available at https://doi. org/10.1017/S1049096516002249.

Oren, Ido. 2003. Our Enemies and US: America's Rivalries and the Making of Political Science. Ithaca, NY: Cornell University Press.

Oren, Ido. 2009. "The Unrealism of Contemporary Realism: The Tension between Realist Theory and Realists' Practice." Perspectives on Politics 7 (2): 283-301. Available at https://doi.org/10.1017/S1537592709090823.

Pachirat, Timothy. 2011. Every Twelve Seconds: Industrialized Slaughter and the Politics of Sight. New Haven, CT: Yale University Press.

Schaffer, Frederic Charles. 1998. Democracy in Translation: Understanding Politics in an Unfamiliar Culture. Ithaca, NY: Cornell University Press.

Sclofsky, Sebastián, and Kevin Funk. 2018. "The Specter That Haunts Political Science: The Neglect and Misreading of Marx in International Relations and Comparative Politics." International Studies Perspectives 19 (1): 83-101. Available at https://doi.org/10.1093/isp/ekxoo7.

Smith, Nicholas Rush. 2019. Contradictions of Democracy: Vigilantism and Rights in Post-Apartheid South Africa. New York: Oxford University Press.

Van Evera, Stephen. 1997. Guide to Methods for Students of Political Science. Ithaca, NY: Cornell University Press.

Yanow, Dvora. 2014. "Thinking Interpretively: Philosophical Presuppositions and the Human Sciences." In Interpretation and Method: Empirical Research Methods and the Interpretive Turn, second edition, eds. Dvora Yanow and Peregrine Schwartz-Shea, 5-26. New York: Routledge.

Yanow, Dvora, and Peregrine Schwartz-Shea (eds.). 2006. Interpretation and Method: Empirical Research Methods and the Interpretive Turn. First edition. Armonk, NY: M.E. Sharpe.

Yanow, Dvora, and Peregrine Schwartz-Shea. 2007. "The Methods Café: An Innovative Idea for Methods Teaching at Conference Meetings." PS: Political Science $\mathcal{E}$ Politics 40 (2): 383-86. Available at https://doi.org/10.1017/S1049096507070655.

Yanow, Dvora, and Peregrine Schwartz-Shea (eds.). 2014. Interpretation and Method: Empirical Research Methods and the Interpretive Turn. Second edition. New York: Routledge. 